\title{
General Discussion to papers of Dr Shand and Dr McClemont, and Mr Nuseibeh and W. El-Masri
}

Chairman: Mr E. GRIFFIths. Could we have any questions now to the two authors of these two papers please. I myself would like to ask $\mathrm{Dr} \mathrm{McClemont}$ how do you spell the second carethrum is it? Sounds like a polyp.

Dr MCClemont. C o r e t h i u m.

Mr E. GRIfFiths. Thank you. The price, can you tell us something about the cost of this, you mentioned that it was a factor in the cost of it?

Dr MCClemont (G.B.) I am sorry I don't know the price of Corethium off hand because we were fortunate to be using it on a trial basis in Edinburgh.

MR E. GRIFFITHS. I see, thank you. Sir Ludwig, please ?

Sir Ludwig GuttmanN (G.B.). If we introduce a new drug for dissolving the sloughs I think it is important that we make comparative examinations with the usual very simple procedure just to excise the slough which I consider as an emergency procedure. We must remember that the slough is a very poisoning protein and the longer it is left in situ the less good is the general condition of the patient as a result of toxic absorption. In your case Dr McClemont for instance where half of the slough was still left you could see the enormous vascular reaction of the skin around the sore. Now this shows how the organism has to deal with to resolve the slough. There are scientific methods to determine the rate of healing whatever local treatment we are using. Making drawings of the sores as I have described and then comparing the rate of healing of a given new treatment with the very simple method of excising the slough immediately and clean it and let it granulate. Unfortunately you didn't show us the end results of all this. We should consider the treatment of pressure sores as a scientific method as described in the literature. Unless we do that we will always have presentations of cases with any new pharmacological procedure under the sun without comparison. The same applies of course to the application of ultra-violet light in the treatment of sores. When I started at Stoke Mandeville all my physiotherapists were full of admiration of ultraviolet treatment. In my lectures to physiotherapists the monotonous question in the discussion was 'What are your views about ultra-violet we find it very successful.' $M y$ answer was: 'Could you please explain to me your technique, why you are so keen on ultra-violet?' The answer was this: 'The doctor or nurse get fed up with the treatment of the sore, the nurse asks us to help and take over. What we are doing is to clean the surroundings of the sore, clean the sore itself with peroxide and saline, then apply the ultra-violet and afterwards cover the sore with saline dressing and seal it up completely with elastoplast to prevent re-infection.' My answer was 'This is excellent. Continue with this treatment with one exception: leave out the ultra-violet for you have applied the proper basic principles of treatment which can be scientifically compared with any other procedures.'

MR N. KRISHNAN (G.B.). Regarding Mr Nuseibeh's and El Masri's paper there are two or three points that I would like to make. I was particularly impressed by the first indication that was stated, the breakdown in the same site. Now we are dealing with a large number of cases, with patients with severe gluteal atrophy who are in fact sitting on two ischiae and two trochanters, a very large number of them do that. Now what I want to ask them is: Is there a case in their opinion that once having done radical surgery recurrence is avoided by producing more soft tissue substance between what is left of the bony prominence and the skin particularly in the ischial site? Flap procedures in the ischial site is probably quite unnecessary and from our experience in Southport has been extremely rare that ischial sores have been treated by flaps, but we do use muscle roll up to produce some sort of cushion effect between the excised bone and the skin, hoping that this will probably prevent a recurrence because there is some soft tissue 
barrier between the two. But when it comes to trochanteric sores I am less enthusiastic because needless to say in any surgical exercise, if you can excise it and leave it its fine, it is ideal and there should never be an argument on that point. But can we really leave it? In a flexed patient when with a flexed hip the skin is very tight over a very tight trochanter. The patients that were shown in the slide are ideal patients but do they represent all the patients? What I would like to ask them, is there an indication for flap surgery in trochanteric sores, if so what would they consider as the indication?

MR GRIFFITHS. Thank you, Mr Krishnan. Would one of the authors like toMr Nuseibeh, please?

MR I. M. Nuseibeh (G.B.). Thank you, Mr Krishnan. I can say that from I975 until now, we have operated on 260 patients with trochanteric sores and as a matter of fact the only time I used the flap method was 2 months ago and this is why it was excluded from the series which means we have treated all our sores with this method, and unfortunately, Krishnan must have missed the first slide which shows a very huge trochanteric sore which, following the understanding of excision and then rendering it clean then, as we said, we applied grafts to make it shrink and by the approximation. The slide which showed the approximation rendered the closure very easy indeed. Now you said about tension, well, as Mr El-Masri said in the paper we allow tension in the deepest layer and that's the only layer, and as a matter of fact I got this tip from the plastic surgeon in Southport, who said to me, the most underlying soft tissue can bear that tension and from there I had no problem at all except the figure which you have seen of recurrences. Now you mentioned about ischial sores. I think the recurrence of the ischial sore depends on how much bone you have taken and how it was taken also because what happens if the patient is lying flat and prone on his face and the operator chips the bone and does partial ischiectomies. I don't say we didn't have recurrences because we did have one or two recurrences but you always will have recurrences as regards sores.

Mr E. Griffiths. Thank you, Dr Nuseibeh. I think one question, Dr Shrosbree.

Dr R. D. Shrosbres ( $S$. Africa). I was very interested in Dr McClemont's paper. In fact we've just recently started a trial on Reprosin and so far we've been quite impressed with it. Particularly on the second paper I'd like to ask the authors, they've got a very low incidence of cervical cases with sore repair I4 per cent. Am I correct in this or did I misunderstand that you only had I4 per cent? Now I would like to know what is the incidence of sores in cervical patients because surely you should have a higher incidence of sores in cervical patients than in thoracic and lumbar patients because they've got arms? This is our experience, our cervical patients have many more sores, especially those that we discharge home.

MR GRIFFITHS. Could Dr Nuseibeh answer the question on the proportion?

DR SHROSBREE. In your incidence of sores you said there were I4 per cent were cervicals. Is this correct or have I misunderstood you?

Mr I. Nuseibeh (G.B.). No, that was I9 per cent.

MR GRIFFITHS. Dr McClemont a final word, have you anything to say or are you happy with the discussion?

DR MCClemont. If I can just answer that last comment that we also find that our cervicals are less prone to pressure sores than the others, but I would also like to assure Sir Ludwig that we are using surgery but obviously very seldom does a sore come straight in that is immediately ready to go to surgery.

MR GRIFFITHS. Thank you very much to both these authors. 